\title{
MARKERS OF ATOPIC REACTIVITY IN THE PUPILS WITH SEVERE BRONCHIAL ASTHMA
}

\author{
Elena Koloskova \\ Department of Pediatrics and Children's Infectious Diseases \\ Higher state education institution of Ukraine "Bukovinan State Medical University" \\ 207A Ruska str., Chernivtsy, Ukraine, 58023 \\ Leonid Bezrukov \\ Department of and Children's Infectious Diseases \\ Higher state education institution of Ukraine "Bukovinan State Medical University" \\ 207 A Ruska str., Chernivtsy, Ukraine, 58023 \\ Uliana Marusyk \\ Department of Pediatrics and Children's Infectious Diseases \\ Higher state education institution of Ukraine "Bukovinan State Medical University" \\ 207 A Ruska str., Chernivtsy, Ukraine, 58023 \\ sunocher@ukr.net \\ Tatiana Lobanova \\ Department of Pediatrics and Children's Infectious Diseases \\ Higher state education institution of Ukraine "Bukovinan State Medical University" \\ 207 A Ruska str., Chernivtsy, Ukraine, 58023 \\ Christina Burenyuk \\ Department of Pediatrics and Children's Infectious Diseases \\ Higher state education institution of Ukraine "Bukovinan State Medical University" \\ 207 A Ruska str., Chernivtsy, Ukraine, 58023
}

\begin{abstract}
The aim of the work was to increase the effectiveness of treatment of the severe asthma phenotype in school-age children, taking into account the diagnostic value of atopic reactivity indicators. The study involved 30 pupils with severe asthma and 30 children with moderate-heavy version of it. Amid severe asthma increases risk of higher concentrations of IL-4 and IL-5 in the serum, and almost in every second child was observed the increased concentrations of Ig E (more than 545,3 IU/mL, odds ratio was $1,9(95 \%$ CI 1,1-3,4). In the group of patients with severe asthma were significantly more frequent cases of the skin hypersensitivity to household allergens with respect to the members of the second group. There were separated the indices of clinical and epidemiological risk and diagnostic value of some markers of atopic reactivity for verification of the severe asthma phenotype. It was established that the development of severe asthma in children marked tendency to reduce the metabolic activity of eosinophilic granulocytes in blood (in terms of intracellular content of cationic proteins and peroxidase) and phagocytic ability of these effector cells of allergic inflammation. For the phenotype of severe asthma the risk of high concentration of IL-4 and IL-5 in serum increased in 3,1 times, but this paraclinical test is rather suitable for verification of this phenotype (SP - 84,6\% (95\% Sp 75,9-91,1)) than for its detection (Se-36,4\% (95\% CI 26,9-46,6)).
\end{abstract}

Keywords: bronchial asthma, children, phenotype, interleukins, immunoglobulins.

\section{Introduction}

One of the most pressing problems of modern pediatric is allergic disease in children, including bronchial asthma (BA). According to the WHO, the prevalence of asthma among children is $10 \%$. In different regions of Ukraine this figure ranges from 5 to $9 \%$ of child population [1, 2]. Particularly acute is the question of currently increasing the effectiveness of this disease therapy and achieve a level of control that would allow the child to lead an active social life. 
Imposing the controlling asthma therapy in children should be considered a feature of the phenotype, defined heterogeneous mechanisms of development, however, is almost identical clinical symptoms [3, 4]. Based on the above, taking into account the performance of atopic reactivity in children that reflect the specific pathogenic mechanisms of realization of asthma $[5,6]$, in a comprehensive study of patients will personalize the treatment of asthma and thereby improve treatment of the disease. The aim was to increase the effectiveness of treatment of phenotype of the severe asthma in school-age children, taking into account the diagnostic value of atopic reactivity indicators.

\section{Aim}

The aim of the work was to increase the effectiveness of treatment of severe asthma phenotype in school-age children, taking into account the diagnostic value of atopic reactivity indicators.

\section{Material and methods}

In pulmonology department of Regional Children's Clinical Hospital of Chernivtsy were complexly examined 60 school-age children suffering from asthma in remission. Over the course of the disease patients were divided into two clinical groups. The first (I) clinical group included 30 patients diagnosed with severe asthma. The second (II) clinical group was formed of 30 students, in which was defined the moderate asthma. For the main clinical signs groups of comparison were matched.

The first clinical group was formed of 21 boy (70,0\%) and 9 girls $(30,0 \%)$. The second group included 19 boys $(63,3 \%, \mathrm{P} \varphi>0,05)$ and 11 girls $(36,7 \%, \mathrm{P} \varphi>0,05)$. The average age of patients in the first group was $12,2 \pm 0,5$ years, and in the second group $-11,1 \pm 0,6$ years $(\mathrm{P}>0,05)$. The structure of the first clinical group included $33,3 \%$ of the urban population and $66,7 \%$ of patients from rural areas. Another group was formed of 12 persons (40,0\%) of residents of cities and urban areas and 18 patients $(60,0 \%, \mathrm{P} \varphi>0,05)$, who live in villages. Thus, by sex, age and place of residence clinical comparison group did not differ significantly.

Eosinophilic metabolic activity of white blood cells was determined by intracellular content of cationic protein (in S. U.) method by V. E. Piharevskoho, peroxidase (in S. U.) - by the method of Graham-Knoll [7]. As indicators of the functional state of eosinophilic white blood cells was determined their phagocytic activity (FA, \%) by Mosyahinoyi YE. N. method. The contents of serum total immunoglobulin E (IgE), interleukin-4 (IL-4) and interleukin-5 (IL-5) were determined by enzyme-linked immunosorbent assay (ELISA). Determination of immediate type skin sensitivity to allergens Nonbacterial standard was performed by intradermal tests. To study the atopy was used a standard household, epidermal, pollen and food allergens.

Statistical analysis of the results of research was carried out by methods of variation statistics using statistical program StatSoft Statistica v5.0., and from the perspective of clinical epidemiology determining sensitivity (Se) and specificity (Sp) test and positive (LR+) and negative (LR-) likelihood ratio, as well as the absolute (AR), relative (RR) risks and odds ratios (OR) indicating $95 \%$ confidence interval $(95 \% \mathrm{CI})$.

\section{The results of the study}

The indicators of eosinophilic intracellular cytotoxic substances in children at observation are shown in Table 1.

\section{Table 1}

The indicators of intracellular eosinophilic cationic protein (ECP) and peroxidase (EP) in children of comparison group

\begin{tabular}{|c|c|c|c|}
\hline Clinical group & Number of children & ECP, S. U. & EP, S. U. \\
\hline I & 30 & $0,17 \pm 0,03$ & $1,32 \pm 0,04$ \\
\hline II & 30 & $0,26 \pm 0,02$ & $1,43 \pm 0,02$ \\
\hline \multicolumn{2}{|c|}{ P: I:II } & $<0,05$ & $<0,05$ \\
\hline
\end{tabular}


The evaluation of phagocytic activity of eosinophilic granulocytes in blood between the groups revealed significant differences in observations. Since, in patients of I clinical group medium group index FA of blood eosinophils was $65,8 \pm 2,8 \%$, while in patients of II group $-74,0 \pm 2,4$ ( $p<0,05$ ). The level of FA eosinophilic leukocytes less than $65 \%$ was observed in $69,2 \pm 7,4 \%$ of children with severe asthma, and in $38,8 \pm 8,1 \%$ of patients with a moderate form of the disease $(p \varphi<0,05)$. Reduced to above the level of FA blood eosinophils associated with the risk of the presence of severe asthma phenotype as follows: RR - 2,1 [95 \% CI: 1,4-2,5], AR - 0,4 - odds ratio - 3,6 [ $95 \%$ CI: 2,1-6,3].

Comparative analysis of the IL-4 and IL-5 concentration in serum of clinical students in both groups revealed no differences likely, however, marked a half of growth in single patients with severe asthma. Thus, the average concentration of IL-4 in serum of children in first clinical group was $10,6 \pm 2,1 \mathrm{pg} / \mathrm{ml}$, and in those of the second group $-7,2 \pm 2,5 \mathrm{pg} / \mathrm{ml}(\mathrm{p}>0,05)$. The average content of interleukin-5 in the clinical group was $35,8 \pm 15,7 \mathrm{pg} / \mathrm{ml}$ and $8,6 \pm 4,3 \mathrm{pg} / \mathrm{ml}$ ( $\mathrm{p}>0,05)$, respectively, and testified four times a day in excess of the marker of first clinical group. Despite the lack of significant differences of these cytokines concentration in the blood serum of children in the comparison groups, nearly in one of three patients $(36,4 \%)$ on the phenotype of severe asthma was recorded significantly increased content of IL-4 (more than 10,0 pg/ml), while in patients of the second group - only 15,5\% of cases ( $p \varphi<0,05$ ). This specificity of the above concentrations of IL-4 in peripheral blood of pupils as the verification test of severe asthma phenotype was 84,6\% (95\% CI 75,9-91,1), but sensitivity only $36,4 \%$ (95 \% CI 26,9-46,6), the odds ratio was 3,1 (95\% CI 1,5-6,2). On the one hand, it highlights the presence of other inflammatory sub phenotype in children with severe asthma phenotype, and the other one the high specificity of this test in the verification of asthma-phenotype.

It is established that the content of total Ig E in serum in all virtually surveyed patients $(95,1 \%)$ is higher than in the normal population of healthy children $(120 \mathrm{IU} / \mathrm{ml})$, but in patients of the first clinical group it was somewhat higher. Thus, the concentration of total immunoglobulin E in serum of pupils with severe asthma was $813,5 \mathrm{IU} / \mathrm{ml}$, and in those of other clinical groups was $685,3 \mathrm{IU} / \mathrm{ml}$ ( $p>0,05$ ). Whey content of total IgE, which exceeded 545,3 IU/ml, was recorded in $56,6 \%$ of children of first clinical group and only in $43,4 \%$ of the second $(p>0,05)$ comparison group.

In conducting intradermal allergy tests was revealed that in patients of the first group most often occurs increased sensitivity to household allergens and pollen, while children in other clinical groups - to food allergens (Fig. 1).

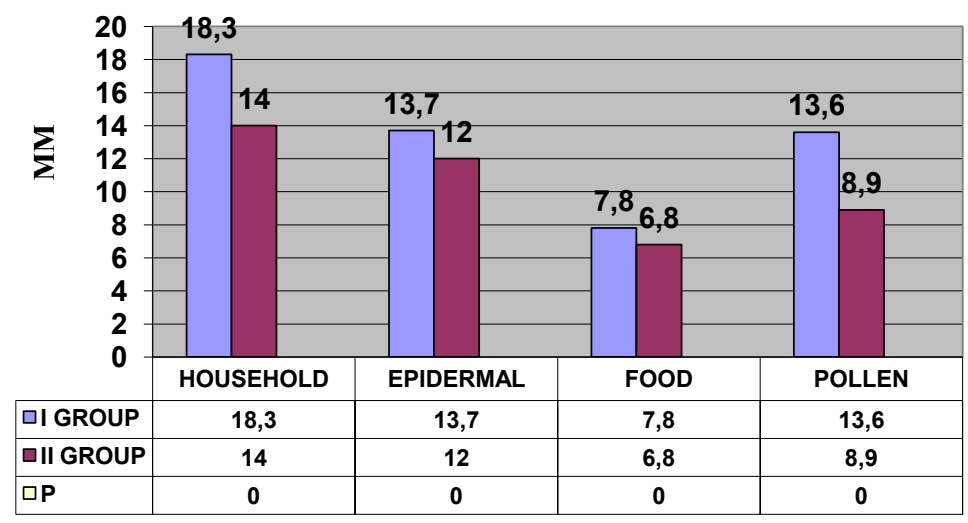

Fig. 1. Skin sensitivity (size of the papules) to allergens in clinical group children

It should be noted that severe asthma more likely associates with the presence of increased skin sensitivity to household allergens. Thus, the amount of congestion in the sample household allergens more than $15,0 \mathrm{~mm}$ was recorded in $81,5 \%$ of children in the first group and only in $51,9 \%$ of persons $(\mathrm{p} \varphi<0,05)$ from the second one.

Performance of diagnostic value of increased skin sensitivity to household allergens as the verification test phenotype of severe asthma, was as follows: sensitivity - 81,5\% (95 \% CI 72,5-88,5), specificity - 48,1 \% (95\% CI 37,9-58,4) LR + - 1,5 and LR - 0,3. Increased sensitivity to domestic allergens (hyperemia more than $15,0 \mathrm{~mm}$ ) associated with the risk of having severe asthma pheno- 
type as follows: attributive risk - 0,3, the relative risk was equal to 2,2 (95\% CI 1,7-2,7), at odds ratio - 4,1 (95\% CI 2,1-7,7).

\section{Discussion}

According to the literature in almost half of patients (40-60\% according to different authors) $[1,8]$ developed asthma that is difficult to treat. It is believed that the inefficiency of controlling asthma therapy [3], due, in particular, to the presence of different asthma phenotypes, such phenotype as "severe asthma" $[5,9,10]$.

Clinical phenotypes of severe asthma need a lot of attention because $80 \%$ of the total cost of asthma accounts is for patients suffering from its severe form [11]. As a result of current multicenter study it is known that severe asthma is independent phenotype of the disease, which has only its inherent characteristics [12]. Analysis of outputs and asthma symptoms study «The Melbourne Asthma Study» showed the heavier asthma in child, the less chance of remission in adults [13, 14]. According to many contemporary researchers phenotype of severe asthma in children is unique; it is different from the phenotype of mild and moderate asthma and severe asthma from adult clinical and functional parameters, biological markers of inflammation, in response to therapy and prognosis [15].

Based on current published data that damaging effect eosinophilic polymorphonuclear leukocytes implemented by degranulation and the release of extracellular space in specific aggressive substances, particularly cationic proteins and peroxidase [14, 15], we thought it appropriate to determine the intracellular content of these substances in the blood eosinophilic granulocytes children in the comparison group to assess their clinical significance in detecting severe asthma compared to moderate option.

In children with severe asthma phenotype intracellular content of eosinophilic cationic protein and peroxidase was significantly lower in relation to patients with moderate asthma. The results may indicate that eosinophilic white blood cells as key effector cells of allergic inflammation, take an active part in the implementation of severe asthma in children with increased needs for cytotoxicity through their active degranulation.

The differences in the main marker phagocytosis, in our opinion, involved more confirmed eosinophilic granulocytes in the blood of allergic inflammation by severe asthma and eosinophilic exhaustion of functional activity of leukocytes in the persistence of severe inflammation.

Important indicators of chronic inflammation in asthma is the content of serum IL-4 and IL-5, the biological effects are associated with the regulation of the synthesis of immunoglobulin E and support eosinophilic inflammation in the respiratory tract $[16,17]$. Since the development of asthma always associated with congenital, genetic determination hyper $\operatorname{IgE}[16,18,19]$, we studied its contents in serum of examined children.

Thus, in most patients with severe asthma was observed high concentration of immunoglobulin E, IL-4 and -5 in the serum that indirectly reflects the severity of inflammation in this cohort of people. The trend to higher content of interleukin -4 and -5 in serum of children with severe asthma, which is found in the study, due probably to the expressive airway inflammation [20].

In conducting intradermal allergy tests was revealed significantly higher sensitivity in children with severe asthma, which coincides with the opinion of some scholars [21] who believe that the leading mechanism of this phenotype of asthma - atopic one.

\section{Conclusion}

1. With the development of severe asthma in children was marked tendency to reduce the metabolic activity of eosinophilic granulocytes of blood (in terms of intracellular content of cationic proteins and peroxidase) and phagocytic ability of these effector cells of allergic inflammation.

2. For the phenotype of severe asthma in 3,1 times increased the risk of high concentration of IL-4 and IL-5 in serum, but this paraclinical test rather suitable for verification of this phenotype (SP - 84,6 \% (95 \% Sp 75,9-91,1)) than for its detection (Se - 36,4 \% (95 \% CI 26,9-46,6)).

3. Concentration of total immunoglobulin $\mathrm{E}$ in serum exceeding 545,3 IU/ml in 2 times increased the chances of the presence of severe asthma in children. 
4. Increased sensitivity to domestic allergens (hyperemia more than $15,0 \mathrm{~mm}$ ) allows to verify the specificity $81,5 \%$ of severe asthma and personalize treatment policy in these patients.

\section{References}

[1] Gnatejko, O., Sadova, O. (2009). Some aspects of early diagnosis of asthma in children. Child health, 5 (20), 34-38.

[2] Chung, K. F., Wenzel, S. E., Brozek, J. L., Bush, A., Castro, M., Sterk, P. J. et. al (2013). International ERS/ATS guidelines on definition, evaluation and treatment of severe asthma. European Respiratory Journal, 43 (2), 343-373. doi: 10.1183/09031936.00202013

[3] GINA-Report-2012 (E-resource). Available at: http://ginaasthma.org

[4] Bush, A., Saglani, S. (2010). Management of severe asthma in children. The Lancet, 376 (9743), 814-825. doi: 10.1016/s0140-6736(10)61054-9

[5] Lötvall, J., Akdis, C. A., Bacharier, L. B., Bjermer, L., Casale, T. B., Custovic, A. et. al (2011). Asthma endotypes: A new approach to classification of disease entities within the asthma syndrome. Journal of Allergy and Clinical Immunology, 127 (2), 355-360. doi: 10.1016/j.jaci.2010.11.037

[6] Hedlin, G., Bush, A., Lodrup Carlsen, K., Wennergren, G., De Benedictis, F. M., Melen, E. et. al (2010). Problematic severe asthma in children, not one problem but many: a GA2LEN initiative. European Respiratory Journal, 36 (1), 196-201. doi: 10.1183/09031936.00104809

[7] Green, R. H., Pavord, I. (2012). Stability of inflammatory phenotypes in asthma. Thorax, 67 (8), 665-667. doi: 10.1136/thoraxjnl-2012-201657

[8] Lang, A., Carlsen, K. H., Haaland, G., Devulapalli, C. S., Munthe-Kaas, M., Mowinckel, P., Carlsen, K. (2008). Severe asthma in childhood: assessed in 10year olds in a birth cohort study. Allergy, 63 (8), 1054-1060. doi: 10.1111/j.1398-9995.2008.01672.x

[9] Bush, A., Hedlin, G., Carlsen, K.-H., de Benedictis, F., Lodrup-Carlsen, K., Wilson, N. (2008). Severe childhood asthma: a common international approach? The Lancet, 372 (9643), 1019-1021. doi: 10.1016/ s0140-6736(08)61422-1

[10] Simões, S. de M., Cunha, S. S. da, Barreto, M. L., Cruz, Á. A. (2010). Distribuição da gravidade da asma na infância. Jornal de Pediatria, 86 (5), 417-423. doi: 10.1590/s0021-75572010000500011

[11] Franco, R., Nascimento, H. F., Cruz, A. A., Santos, A. C., Souza-Machado, C., Ponte, E. V. et. al (2009). The economic impact of severe asthma to low-income families. Allergy, 64 (3), 478-483. doi: 10.1111/j.1398-9995.2009.01981.x

[12] Silvestri, M., Pistorio, A., Battistini, E., Rossi, G. A. (2010). IgE in childhood asthma: relevance of demographic characteristics and polysensitisation. Archives of Disease in Childhood, 95 (12), 979-984. doi: 10.1136/adc.2009.163667

[13] Soyer, O. U., Akdis, M., Ring, J., Behrendt, H., Crameri, R., Lauener, R., Akdis, C. A. (2012). Mechanisms of peripheral tolerance to allergens. Allergy, 68 (2), 161-170. doi: 10.1111/all.12085

[14] Lora-mladshego, G., Fishera, T., Adel'mana, D. (Eds.) (2000). Klinicheskaya immunologiya i alergologiya [Clinical Immunology and Allergology]. Moscow: Practice.

[15] Chung, K. F., Wenzel, S. E., Brozek, J. L., Bush, A., Castro, M., Sterk, P. J. et. al (2013). International ERS/ATS guidelines on definition, evaluation and treatment of severe asthma. European Respiratory Journal, 43 (2), 343-373. doi: 10.1183/09031936.00202013

[16] Ogorodova, L., Petrovskij, F., Korostovcev, D., Alikova, O. (2004). Severe asthma in children: results of a multicenter national study «NABAT». Allergology, 3, 3-9.

[17] Barreto M.L., Cunha S. S., Alcantara-Neves N., Carvalho L. P., Cruz A. A., Stein R. T., et al. (2006). Risk factors and immunological pathways for asthma and other allergic diseases in children: background and methodology of a longitudinal study in a large urban center in Northeastern Brazil (Salvador-SCAALA study). BMC Pulmonary Medicine, 6 (1), 15. doi:10.1186/1471-2466-6-15

[18] Nagakumar, P., Thomas, H. (2013). Management of severe asthma in children. Paediatrics and Child Health, 23 (7), 291-295. doi: 10.1016/j.paed.2013.05.010

[19] Cruz, A. A., Bousquet, P. J. (2009). The unbearable cost of severe asthma in underprivileged populations. Allergy, 64 (3), 319-321. doi: 10.1111/j.1398-9995.2009.02026.x

[20] Waserman, S., Nair, P., Snider, D. (2012). Local and systemic immunological parameters assjciated with remission of asthma symptoms in children. Allergy, asthma and clinical immunology, 8 (16), 1-14.

[21] Kostromina, V. P., Rechkina, O. O., Mel’ny`k, K. O., Doroshenkova, A. S., Stry`zh, V. O., Yaroshhuk, L. B. (2013). Risk factors of bronchial asthma in children. Asthma and Allergies, 2, 21-23. 